\title{
Reappraisal learning curve of laparoscopic Roux-en Y gastric bypass: retrospective results of one hundred and eight cases from a low-volume unit
}

\author{
Hung-Chieh $\mathrm{LO}^{1,2^{*}} \mathbb{0}$ and Sheng-Mao $\mathrm{Wu}^{1}$
}

\begin{abstract}
Background: This study aimed to reevaluate the learning curve of laparoscopic Roux-en Y gastric bypass (LRYGB) in the modern era while considering a single surgeon's experience.

Methods: From the beginning of our LRYGB practice, all patients who met the regional criteria and underwent primary LRYGB were retrospectively enrolled. Patients with a body mass index (BMI) $>50 \mathrm{~kg} / \mathrm{m}^{2}$ were excluded. Those who underwent surgery in 2016-17, 2018 and 2019 by a single surgeon with 10+years of laparoscopic experience were assigned to groups A, B and C, respectively. The patient demographics and 30-day outcome data, including the operation time, length of stay (LOS), emergency room visits, readmission, and reoperation, were compared among the groups.

Results: One hundred and eight patients met the inclusion criteria; 36,38 , and 34 patients were assigned to groups $A, B$ and $C$, respectively. There were no differences in age, sex distribution or common comorbidities among the groups; however, B had a lower BMI (35.1 kg/m² vs. $\left.37.0 \mathrm{~kg} / \mathrm{m}^{2}\right)$ and a higher rate of hypertension (44.7\% vs. 22.2\%) than group A. The operation time was markedly reduced (96.1 min and $114.9 \mathrm{~min}, \mathrm{p}<0.001$ ), and the LOS was shortened ( 2.2 days and 2.9 days, $p<0.001$ ) in group $B$ compared to group $A$ and remained stationary in group $C$, with no further reduction in 30-day complications.

Conclusion: The learning process of LRYGB can be shortened to approximately 30 cases if conducted selectively by experienced laparoscopic surgeons. Further follow-up is required to verify the long-term safety and applicability in other patient subgroups.
\end{abstract}

Keywords: Obesity, Roux-en Y gastric bypass, Bariatric, Learning curve

\section{Background}

The prevalence of obesity has nearly tripled over the past four decades [1]. Bariatric surgery has been shown to be the only treatment with long-term effectiveness for morbid obesity and obesity-related comorbidities [2]. Until

\footnotetext{
*Correspondence: carfishcat@yahoo.com.tw

1 Division of Trauma and Emergency Surgery, Department of Surgery,

Wan Fang Hospital, Taipei Medical University, Taipei, Taiwan

Full list of author information is available at the end of the article
}

recently, laparoscopic Roux-en Y gastric bypass (LRYGB) was acknowledged as the standard bariatric-metabolic procedure and was performed secondarily only after laparoscopic sleeve gastrectomy (LSG) [3]. However, LRYGB is generally considered more technically demanding and has higher complication rates than LSG [4]. Accordingly, a steep learning curve was generally required to meet its safety standards [5]. As the literature often focused on the results of centers of excellence and high-volume 
centers, only a few studies addressed the learning process in a low-volume center [6].

Traditionally, surgical procedures were mostly learned through observation, on-the-spot assistance or field practice. As time progressed, a new era of surgical education platforms emerged [7]. Online media resources have been proven to be valuable information resources that can improve the learning experience if appropriately used [8] and served as a valuable method in our learning process. Moreover, as learning curves can reportedly be largely reduced based on advanced laparoscopic skills and preemptive bariatric experience [9], the aim of this study was to reappraise the learning curve of LRYGB by a single practicing laparoscopic surgeon with $10+$ years of experience in various gastrointestinal surgeries and obtain initial experience performing one-anastomosis gastric bypass (OAGB-MGB) [10]. Meanwhile, for lowvolume practices, it is important to maintain safety profiles and carefully audit the results. Our goal was to verify both the peri-operative efficiency in terms of the operation time, length of stay (LOS) and safety regarding all 30-days outcome measures and 1-year weight loss.

\section{Methods}

This retrospective cohort study was conducted at a private university affiliated hospital. From January 2016 to December 2019, all data of consecutive patients who underwent primary LRYGB under the care of a single surgeon were retrospectively collected from a prospectively maintained database after obtaining institutional review board approval (TMU-JIRB No.: N202004071). The patients were eligible for bariatric/metabolic procedures if they met the regional criteria proposed by the International Federation for the Surgery of Obesity and Metabolic Disorders (IFSO) [11]. There are no specific exclusion criteria; however, a body mass index $(\mathrm{BMI})>50 \mathrm{~kg} / \mathrm{m}^{2}$ was not considered suitable for LRYGB in our initial practice because gastric bypass is generally less effective in these patients [12], and these patients have a higher rate of complications than patients with a lower BMI [13]. In all other patients, the procedure selection among LRYGB, LSG and OAGB-MGB was conducted through a shared decision-making process after full clearance of efficacy and risks based on the literature at the time in the outpatient clinic. The final decision was made using a shared decision-making process after fully considering the potential long-term outcomes of each procedure.

To assess the learning process, the patients were divided into three groups based on their surgery time and case distributions as follows: group A included initial patients who underwent primary LRYGB in 201617. Groups $B$ and $C$ included patients who underwent surgery in 2018 and 2019, respectively. All patients underwent complete preoperative evaluations. A simplified and pragmatic enhanced recovery after surgery (ERAS) protocol consistent with the available guidelines at that time that utilized basic and essential changes was fully initiated in January 2017 [14]. In addition to the previous standard of care, bolus dexamethasone $(10 \mathrm{mg})$ and droperidol $(0.625 \mathrm{mg})$ were introduced for postoperative nausea and vomiting prophylaxis. According to the multimodal analgesic regimen, a particular emphasis was placed on the total elimination of opioid medication and its equivalent usage under the aid of laparoscopically guided transversus abdominis plane block. Nasogastric tube, abdominal drainage and urinary catheter placement were discontinued after the ERAS implementation. With routine and on-demand multimodal analgesics and antiemetic agents (i.e., Dynastat, acetaminophen, and ondansetron) postoperatively, discharge was commenced on the first postoperative day if a liquid diet was tolerable.

The recorded parameters, including the patients' demographic factors and anthropometric data; all relevant outcome measures, including the operation time, LOS and 30-day complications, such as emergency room (ER) visits, readmission, reoperation and conversion; and one year weight loss results were compared between group $B$ and group $A$ and between group $C$ and group $B$ to verify the impact of the learning curve and audit for any quality alterations.

\section{Surgical technique}

LRYGB was performed using a four-abdominal trocar technique and a Nathanson liver retractor. Our technique comprises linear stapling to create a lesser curve-based, $30-\mathrm{ml}$ vertical gastric pouch over a $32 \mathrm{Fr}$. calibrating tube with 100-cm ante-colic, ante-gastric Roux limb and 100$\mathrm{cm}$ biliopancreatic limb. The enterotomies post both stapling anastomoses were hand-sewn closed. Both mesenteric defects were routinely closed with nonabsorbable sutures. A section of the greater omentum is not routinely performed.

\section{Data collection and statistical analysis}

The Statistical Package for the Social Sciences software version 20.0 (SPSS Inc., Chicago, Illinois, USA) was used to perform the statistical analyses. The descriptive results of the continuous variables are presented as the means \pm standard deviations, and the categorical variables are presented as counts and percentages. The categorical data were analyzed using Fisher's exact test and an unpaired t-test was used to analyze the parametric data when appropriate. The statistical significance tests were two-sided, with a level of significance of 0.05 . 


\section{Results}

Between January 2016 and December 2019, in total, two hundred and four patients underwent bariatric or metabolic procedures in our unit. Among these patients, three patients underwent a nonprimary procedure, five patients underwent LSG, and 39 patients underwent OAGB-MGB in 2016-17. In 2018, two patients underwent a nonprimary procedure, two patients underwent LSG, and 18 patients underwent OAGB-MGB. In 2019, six patients underwent a nonprimary procedure, one patient underwent LSG, and 20 patients underwent OAGB-MGB. All patients who did not fulfill the inclusion criteria were excluded from the analysis, and ultimately, one hundred and eight patients were enrolled in this study. Of these patients, 36 patients who underwent primary LRYGB in 2016-17 were assigned to group A. The other 38 and 34 patients who underwent primary LRYGB in 2018 and 2019 were assigned to group B and group C, respectively.

The demographic details and clinical characteristics are outlined in Table 1. There were no significant differences between group B and group A with respect to age, sex, preoperative weight or incidence of common comorbidities. However, the patients in group B had a significantly lower BMI $\left(35.1 \pm 3.8 \mathrm{~kg} / \mathrm{m}^{2}\right.$ vs. $37.0 \pm 3.6 \mathrm{~kg} / \mathrm{m}^{2}$; $\mathrm{p}=0.03)$ and a higher rate of hypertension (HTN) $(44.7 \%$ vs. $22.8 \% ; \mathrm{p}=0.04)$ than those in group A. Group $\mathrm{C}$ did not differ from group $\mathrm{B}$ in terms of age, female proportion, or baseline BMI, but group $\mathrm{C}$ had a tendency toward a higher rate of diabetes mellitus (32.4\% vs. $21.1 \%$; $\mathrm{p}=0.28)$ and a lower rate of HTN $(35.3 \%$ vs. $44.7 \%$; $\mathrm{p}=0.41)$ than group $\mathrm{B}$. A significantly higher incidence of previous nonbariatric surgeries was found in group $\mathrm{C}$ compared to group B ( $35.3 \%$ vs. $23.7 \%$; $\mathrm{p}=0.28)$. However, the main difference was observed among gynecological procedures exclusively for benign lesions. We also did not encounter any severe bowel adhesion required a change in the treatment plan throughout the study.

The surgical characteristics and outcomes are listed in Table 2. As shown, in the table only one concomitant procedure, i.e., a partial gastrectomy for benign lesions, was carried out in group A. The mean operation time in group B was significantly decreased compared to that in group A (96.1 min vs. $114.9 \mathrm{~min}$, respectively; $\mathrm{p}<0.001$ ) and was similar between group B and group C (96.1 min vs. 92.1 min; $p=0.20$ ). The mean LOS was also markedly shortened in group B compared to group A ( $2.2 \pm 0.5$ days vs. $2.9 \pm 0.8$ days; $\mathrm{p}<0.001)$ and was similar, at 2.2 days, between group $C$ and group $B(p=0.70)$. All procedures were performed with a laparoscopic approach without open conversion. The 30-day complication rate did not differ between groups B and A ( $2.6 \%$ vs. $2.8 \% ; \mathrm{p}=0.97)$ or between groups $\mathrm{C}$ and $\mathrm{B}(2.9 \%$ vs. $2.6 \%$; $\mathrm{p}=0.62)$.

In total, five patients experienced 30-day adverse events, and three of these cases were classified as complications. One patient in group A was readmitted for gastrojejunostomy stenosis on postoperative day 30, which was relieved following a single session of balloon dilatation. In group B, two patients visited the ER after discharge as follows: one patient visited for nonspecific

Table 1 Demographic and clinical characteristics of the patients, mean (SD)

\begin{tabular}{|c|c|c|c|c|c|}
\hline & $\begin{array}{l}\text { Group A } \\
(\mathrm{N}=36)\end{array}$ & $\begin{array}{l}\text { Group B } \\
(\mathrm{N}=38)\end{array}$ & $\begin{array}{l}\text { Group A vs. B } \\
\text { p-value }\end{array}$ & Group C $(N=34)$ & $\begin{array}{l}\text { Group B vs. C } \\
\text { p-value }\end{array}$ \\
\hline Age (years) & $35.3 \pm 10.3$ & $38.5 \pm 9.1$ & 0.16 & $39.6 \pm 9.2$ & 0.62 \\
\hline \multicolumn{6}{|l|}{ Sex, n (\%) } \\
\hline Male & $14(38.9)$ & $15(39.5)$ & & $15(44.1)$ & \\
\hline Female & $22(61.1)$ & $23(60.5)$ & 0.96 & $19(55.9)$ & 0.69 \\
\hline Preoperative weight (kg) & $102.8 \pm 16.7$ & $95.8 \pm 17.1$ & 0.08 & $98.7 \pm 16.0$ & 0.44 \\
\hline $\mathrm{BMI}\left(\mathrm{kg} / \mathrm{m}^{2}\right)$ & $37.0 \pm 3.6$ & $35.1 \pm 3.8$ & $0.03^{*}$ & $36.3 \pm 3.2$ & 0.13 \\
\hline \multicolumn{6}{|l|}{ Comorbidities, n (\%) } \\
\hline Diabetes mellitus & $10(27.8)$ & $8(21.1)$ & 0.50 & $11(32.4)$ & 0.28 \\
\hline Hypertension & $8(22.2)$ & $17(44.7)$ & $0.04^{*}$ & $12(35.3)$ & 0.41 \\
\hline Dyslipidemia & $18(50)$ & $21(55.3)$ & 0.65 & $18(52.9)$ & 0.84 \\
\hline Prior operation, n (\%) & $10(27.8)$ & $9(23.7)$ & 0.69 & $12(35.3)$ & 0.28 \\
\hline Viceral $^{\mathrm{a}}$ & 3 & 3 & & 4 & \\
\hline Gyn ${ }^{b}$ & 9 & 6 & & 10 & \\
\hline
\end{tabular}

The data are expressed as the means \pm standard deviations or numbers and percentages

$B M /$ body mass index

a All with laparoscopic cholecystectomy and/or laparoscopic appendectomy

b Gynecology procedures exclusively for benign lesion

*p $<0.05$ 
Table 2 Surgical perspectives and outcomes, mean (SD)

\begin{tabular}{|c|c|c|c|c|c|}
\hline & $\begin{array}{l}\text { Group A } \\
(\mathrm{N}=36)\end{array}$ & $\begin{array}{l}\text { Group B } \\
(\mathrm{N}=38)\end{array}$ & $\begin{array}{l}\text { Group A vs. B } \\
\text { p-value }\end{array}$ & $\begin{array}{l}\text { Group C } \\
(\mathrm{N}=34)\end{array}$ & $\begin{array}{l}\text { Group B vs. C } \\
\text { p-value }\end{array}$ \\
\hline $\begin{array}{l}\text { Concomitant procedure, } \\
\mathrm{n}(\%)\end{array}$ & $1(2.8)$ & 0 & 0.30 & 0 & \\
\hline Op time (min) & $114.9 \pm 29.1$ & $96.1 \pm 13.5$ & $<0.001^{*}$ & $92.1 \pm 12.1$ & 0.20 \\
\hline LOS (days) & $2.9 \pm 0.8$ & $2.2 \pm 0.5$ & $<0.001^{*}$ & $2.2 \pm 0.4$ & 0.70 \\
\hline Conversion & 0 & 0 & & 0 & \\
\hline 30-day complications, n (\%) & $1(2.8)$ & $1(2.6)$ & 0.97 & $1(2.9)$ & 0.62 \\
\hline Stenosis & 1 & 0 & & 0 & \\
\hline Melena & 0 & 0 & & 1 & \\
\hline Hematemesis & 0 & 1 & & 0 & \\
\hline 30-day ER visit, n (\%) & 0 & $2(5.3)$ & 0.16 & $1(2.9)$ & 0.62 \\
\hline 30-day readmission, n (\%) & $1(2.8)$ & $1(2.6)$ & 0.97 & 0 & 0.34 \\
\hline 30-day mortality, n (\%) & 0 & 0 & & 0 & \\
\hline 1-year follow-up, n (\%) & $30(83) \%$ & $30(79) \%$ & & $28(82) \%$ & \\
\hline$\% \mathrm{EWL}$ & $76.4 \pm 18.2$ & $80.6 \pm 19.8$ & 0.40 & $82.4 \pm 14.3$ & 0.70 \\
\hline$\% T W L$ & $26.7 \pm 5.1$ & $25.1 \pm 6.6$ & 0.28 & $28.0 \pm 5.4$ & 0.07 \\
\hline
\end{tabular}

Op operation, LOS length of stay, ER emergency room, \%EWL percentage of excess weight loss, \%TWL percentage of total weight loss

${ }^{*} \mathrm{p}<0.05$

focal abdominal pain, and the other patient, who visited for hematemesis on postoperative day 9 , was readmitted and recovered uneventfully after proper medical treatment. In group $\mathrm{C}$, one patient was noted to have self-limiting melena that subsided under supportive treatment. Another patient visited the ER for lower back pain. The rates of 30-day ER visits and 30-day readmissions did not differ among the groups. There were no reported cases of anastomotic leakage, reoperation or mortality throughout the study period.

Up to 12 months postoperatively, $83 \%$ of the patients in group A, $79 \%$ of the patients in group B and $82 \%$ of the patients in group $C$ were available for follow-up. No statistically significant differences in the percentage of total weight loss (\%TWL) and percentage of excess weight loss (\%EWL) were found. The \%EWL was $76.4 \%, 80.6 \%$, and $82.4 \%$ and the $\% \mathrm{TWL}$ was $26.7 \%, 25.1 \%$ and $28.0 \%$ in groups A, B and C, respectively.

\section{Discussion}

Here, we report the outcomes of 108 initial patients who underwent LRYGB over a 4-year period in a low-volume hospital, indicating the learning curve. By comparing the results among the 3 groups, significant improvements in the operation time and LOS with an acceptably low rate of complications were observed after the initial 36 cases (group A). The present study demonstrated that the learning curve of LRYGB can be safely reduced to $30+$ cases in the modern era under a unique setting.
Because of increasingly complex techniques and dependence on advanced instruments, the acquisition of new laparoscopic skills is considered difficult. When conducting LRYGB in morbidly obese patients, several other inherent technical barriers, such as body habitus, multistep reconstructive procedures involving multiabdominal quadrants and laparoscopic suturing and knot tying skills, are likely to occur. Therefore, this procedure was once rated as a 9.5 on a difficulty scale of 10 , indicating substantial technical difficulty [15]. These skill-related prerequisites can result in adverse consequences during the early phase of practice, especially in a low-volume practice [6]. Traditionally, various educational programs, such as workshops [16], bariatric fellowships [17] and systematic training programs [18], have been available to facilitate this process. In recent years, new-era platforms have emerged, providing another type of auxiliary training approach [7]. Their popularity among medical professionals has increased, as these platforms generally enable more visual and auditory interactions than journals or textbooks [19]. A systematic review of the impact of e-learning demonstrates significant gains in knowledge compared with traditional teaching patterns [20]. In our self-learning process, in addition to traditional learning methods, these online multimedia materials provide considerable references and guidance despite the lack of objective tools for gauging their impact.

By considering a single surgeon's perspective, we retrieved comparative data from the literature discussing the relevant process by a single surgeon (Table 3). Among 
Table 3 List of historical studies involving a single surgeon

\begin{tabular}{|c|c|c|c|c|c|c|c|c|c|}
\hline \multirow[t]{2}{*}{ Authors } & \multirow[t]{2}{*}{ Study period } & \multirow[t]{2}{*}{ Background } & \multirow{2}{*}{$\begin{array}{l}\text { Patients }(\mathrm{n}) \\
\text { Groups inclusion } \\
\text { criteria }\end{array}$} & \multirow{2}{*}{$\begin{array}{l}\mathrm{Age}^{\mathrm{a}} \\
\text { (years)/ } \\
\mathrm{BMI}^{\mathrm{a}}(\mathrm{kg} / \\
\left.\mathrm{m}^{2}\right)\end{array}$} & \multirow[t]{2}{*}{ Learning curve } & \multicolumn{2}{|c|}{$\begin{array}{l}\text { Mean op time } \\
(\min )\end{array}$} & \multicolumn{2}{|c|}{$\begin{array}{l}\text { Complications } \\
\text { (\%) }\end{array}$} \\
\hline & & & & & & Pre-LC & Post-LC & Pre-LC & Post-LC \\
\hline Agrawal et al. [9] & $10-11$ & $\begin{array}{l}\text { Advanced scope } \\
\text { fellowship } \\
\text { laparoscope bari- } \\
\text { atric }\end{array}$ & $\begin{array}{l}74 \\
1 \text { group } \\
\text { primary procedures }\end{array}$ & $\begin{array}{l}45.1 \\
47.7\end{array}$ & $\begin{array}{l}\text { Not } \\
\text { required }\end{array}$ & 160 & n/a & 1.4 & $\mathrm{n} / \mathrm{a}$ \\
\hline Shen et al. [27] & $09-11$ & $\begin{array}{l}\text { Advanced scope } \\
\text { fellowship }\end{array}$ & $\begin{array}{l}60 \\
2 \text { groups } \\
\text { IFSO-APC Criteriab }^{\text {bSO }}\end{array}$ & $\begin{array}{l}34.2 \\
41.5\end{array}$ & 30 & 120 & 80 & 26.7 & 6.7 \\
\hline $\begin{array}{l}\text { Shin et al } \\
{[23]}\end{array}$ & 03 & $\begin{array}{l}\text { Advanced scope } \\
\text { fellowship }\end{array}$ & $\begin{array}{l}100 \\
2 \text { groups } \\
\text { unselective }\end{array}$ & $\begin{array}{l}42.6 \\
47.6\end{array}$ & 50 & 113 & 73 & 32 & 8 \\
\hline Oliak et al. [21] & 99-01 & Advanced scope & $\begin{array}{l}225 \\
3 \text { groups } \\
\text { primary procedures }\end{array}$ & $\begin{array}{l}40 \\
51\end{array}$ & 75 & 189 & 125 & 32 & 15 \\
\hline Huang et al. [28] & $05-07$ & Advanced scope & $\begin{array}{l}100 \\
2 \text { groups } \\
\text { unselective }\end{array}$ & $\begin{array}{l}31.2 \\
43\end{array}$ & 50 & 217 & 105 & 15 & 3 \\
\hline Nguyen et al. [24] & $\mathrm{n} / \mathrm{a}$ & Advanced scope & $\begin{array}{l}150 \\
2 \text { groups } \\
\text { unselective }\end{array}$ & $\begin{array}{l}40 \\
47\end{array}$ & 75 & 250 & $\mathrm{n} / \mathrm{a}$ & 12 & 1 \\
\hline Andrew et al. [22] & 02-04 & Open bariatric & $\begin{array}{l}201 \\
3 \text { groups } \\
\text { unselective }\end{array}$ & $\begin{array}{l}37 \\
49.2\end{array}$ & 70 & 145 & 118 & 19.4 & 11.9 \\
\hline $\begin{array}{l}\text { Ballesta-Lopez et al. } \\
\text { [26] }\end{array}$ & 00-04 & $\begin{array}{l}\text { Advanced scope } \\
\text { LAP BAND }^{\circledR}\end{array}$ & $\begin{array}{l}600 \\
6 \text { groups } \\
\text { unselective }\end{array}$ & $\begin{array}{l}38.7 \\
44.4\end{array}$ & 100 & 166 & 109 & 29.2 & 14 \\
\hline Current study & $16-19$ & $\begin{array}{l}\text { Advanced scope } \\
\text { laparoscope bari- } \\
\text { atric }\end{array}$ & $\begin{array}{l}108 \\
3 \text { groups } \\
\text { primary procedures }\end{array}$ & $\begin{array}{l}37.8 \\
36.1\end{array}$ & $30+$ & 115 & 96 & 2.8 & 2.6 \\
\hline
\end{tabular}

Op operation, $B M /$ body mass index, $n / a$ no data available

a Mean

b IFSO-APC criteria refer to the International Federation for the Surgery of Obesity and Metabolic Disorders Asia Pacific Chapter criteria[11]

them, variability in surgical techniques exists. Moreover, several modifications of traditional methods have occurred; for instance, the retro-colic placement of the Roux limb [21,22] or circular-stapled anastomosis [21, $23,24]$ have largely fallen out of favor. Meanwhile, there are differences among studies in terms of backgrounds, annual hospital volumes and former laparoscopic/bariatric experience levels. Despite the undisputable importance and heightened awareness of proper fellowship training [25], there is no standard teaching approach, and accredited bariatric programs are not globally available. For example, while carried out during different periods, some hospitals conducted other laparoscopic bariatric procedures $[9,26]$ or performed open bariatric surgeries [22], while other hospitals just started after complete fellowship training $[23,27]$ or are based solely on advanced laparoscopic skills $[21,24,28]$. Additionally, the case selection criteria considerably differed. In general, fellowship-trained bariatric surgeons or those conducted the procedures after preceding bariatric experience appear to have a shorter learning curve and implement a more efficient practice. For instance, after completing a monthlong mini-fellowship, Shen et al. achieved a considerably decreased complication rate and proficiency after only 30 cases [27]. In particular, these authors utilized the case selection criteria following the IFSO Asian-Pacific guidelines, which is similar to our research [11]. However, these authors reported an initial complication rate of $26.7 \%$, which included $6.7 \%$ conversion, $10 \%$ reoperation and $5 \%$ leakage rate. While surgeons at high-volume hospitals often have the opportunity to master the procedure in a short period with preferable results [29], Shin et al. participated as assistants in 30 surgeries and conducted the first few surgeries under proctoring. These authors analyzed their first one hundred cases within 5 months and concluded that the learning curve plateaued after 50 surgeries [23]. While these authors realize a marked decrease in the operation times (113 min pre- and $73 \mathrm{~min}$ post-learning curve), they indicated that there was no further notable reduction in complications after the 
learning curve. With particularly vast prior experience in LAP BAND ${ }^{\circledR}$, Ballesta-Lopez et al. also published a large series with marked decreased operative time and LOS after the first 100 surgeries [26]. Particularly, as one of only two studies, in addition to the study by Andrew et al. [22], which was conducted with totally hand-sewn gastrojejunostomy, the authors reported no negligible leakage rate of up to $9 \%$, a $5.1 \%$ reoperation rate (mostly for leakage) and a $29.2 \%$ complication rate. In other studies with only prior advanced laparoscopic experience $[21,24,28]$, the learning curve was slightly longer, and there was a substantially prolonged operation time compared with studies involving surgeons who completed a fellowship [9, 23, 27]. For instance, Oliak et al. reported a series with the highest mean BMI of $51 \mathrm{~kg} /$ $\mathrm{m}^{2}$ and proposed that the learning curve plateaued after 75 surgeries [21]. The surgeons' operative times substantially decreased from 189 min during the first 75 cases and then gradually decreased. Notably, the perioperative complication rates were substantial among all studies both before (32\%) and after the learning curve (15\%). Nguyen et al. evaluated 150 consecutive cases, with the longest mean operation time of $250 \mathrm{~min}$ before the learning curve; these authors also observed that an initial lack of experience ( $<75$ cases) was a major factor associated with major complications and an increased reoperation rate [24]. However, with advanced laparoscopic skills and preemptive bariatric experience, Agrawal et al. suggest that LRYGB can be performed safely with a minimal complications rate of only $1.4 \%$ and effectively without any learning curve required [9]. Notably, our initial results stabilized after only 36 surgeries and we had a low initial 30 -day complication rate of $2.8 \%$. The only difference is that their research was conducted after the completion of fellowship training [9]. However, consistent with these aforementioned studies, a sharp improvement in terms of the operation time was observed in the current study after the learning curve. Similar to the findings reported by Shin et al. [23], we observed no further decrease in the complication rate after the learning curve. Only one patient presented with stenosis, and two other patients presented with hemorrhagic complications as follows: one with hematemesis and one with melena. Considering the reported stenosis rate of 2.2 to $10 \%$ [21, $23,27,28]$ and that the hemorrhagic complication rate ranges from 1 to $3.3 \%$ during the learning process [23, $24,28]$, we deemed our initial results acceptable. Furthermore, there were no cases of mortality, leakage, conversion or other major complications. While prolonged hospital stay is not uncommon after such a procedure. Nguyen et al. noted that $11 \%$ of their cases had an LOS over 4 days [24], and the LOS reportedly ranges between 6 to 6.4 days before the learning curve and 4.8 to 5 days after the learning curve $[27,28]$. We observed a notably shorter LOS, with a mean of 2.9 days before the learning curve and 2.2 days after the learning curve. In addition, only $2.8 \%$ of our patients required hospitalization for more than 3 days. Our learning curve and timespan to reach competency are consistent with the findings of a systemic review that reported between 30 and 70 surgeries [30]. Notably, the consistent outcome obtained in group $B$ and group $C$ can be considered an early achievement of proficiency because we reached this goal within less than 70 accumulative surgeries, while historically, between 70 and 150 surgeries are usually required [30].

Many factors likely contributed to our early desirable results. First, in contrast to most studies with an unselective patient approach $[22-24,26,28]$, patients with a BMI $>50$ were preferably offered alternative treatment modalities considering safety and long-term effectiveness [12, 31]. As a result of this selective approach, the mean BMI of $36.1 \mathrm{~kg} / \mathrm{m}^{2}$ in our series was significantly lower than that in former studies, which ranged from 43 to $51 \mathrm{~kg} / \mathrm{m}^{2}$ [21, 28]. Second, as guidelines for tailored peri-operative care were established in 2016 [14], a pragmatic enhanced recovery protocol was gradually adopted in our unit. Furthermore, our preceding experience with OAGB-MGB may have transferred to subsequent LRYGB and increased its safety [10]. Similarly, comprehensive care and improved techniques have been demonstrated in other studies across different periods [32]. Because only two aforementioned studies included cases after $2010[9,27]$, we believe that general improvements further contribute to this desirable result.

\section{Limitations}

Limited by the selective approach, our result may not be generalizable to all patient subgroups. Nevertheless, a desirable outcome can be accomplished during the learning process via this selective approach. Moreover, because of the retrospective design and nonrandomized nature, the presence of clinical heterogeneity among the groups may compromise their comparativeness.

\section{Conclusion}

In conclusion, the current study shows that a satisfactory learning curve can be safely accomplished in a low-volume center with the complication rates, operation times and LOS plateauing after $30+$ cases. Additional data regarding long-term efficacy, safety and generalizability are required.

\section{Abbreviations}

LRYGB: Laparoscopic Roux-en Y gastric bypass; BMI: Body mass index; LOS: Length of stay; LSG: Laparoscopic sleeve gastrectomy; OAGB-MGB: 
One-anastomosis gastric bypass; IFSO: International Federation for the Surgery of Obesity and Metabolic Disorders; ER: Emergency room; HTN: Hypertension.

\section{Acknowledgements}

Not applicable.

\section{Authors' contributions}

$\mathrm{HC}$ designed the study, performed the surgical procedures, followed the patients, and participated in the data analysis and writing of the manuscript. SM contributed to the data analysis. All authors read and approved the final manuscript.

\section{Funding}

The study was not sponsored and funded by any funding.

\section{Availability of data and materials}

The datasets generated and/or analyzed during the current study are not publicly available due to restrictions by the local Institutional Review Board but are available from the corresponding author upon reasonable request and with permission from the local Institutional Review Board.

\section{Ethical approval and consent to participate}

All procedures performed in studies involving human participants were in accordance with the ethical standards of institutional and/or national research committees and the 1964 Declaration of Helsinki and its later amendments or comparable ethical standards. The research project was approved by the Taipei Medical University-Joint Institutional Review Board (No.: N202004071). Informed consent was waived because no data of the cases were disclosed.

\section{Consent for publication}

Written informed consent for publication was waived because no clinical details and/or clinical images of the cases were disclosed.

\section{Competing interests}

The authors declare that they have no competing interests.

\section{Author details}

${ }^{1}$ Division of Trauma and Emergency Surgery, Department of Surgery, Wan Fang Hospital, Taipei Medical University, Taipei, Taiwan. ${ }^{2}$ Department of Surgery, School of Medicine, College of Medicine, Taipei Medical University, No. 111, Sec. 3, Xinglong Rd., Wenshan Dist., Taipei City 116, Taiwan, ROC.

Received: 27 October 2020 Accepted: 12 January 2021

Published online: 15 February 2021

\section{References}

1. Obesity and overweight. https://www.who.int/en/news-room/fact-sheet s/detail/obesity-and-overweight.

2. Sjöström L, Lindroos AK, Peltonen M, Torgerson J, Bouchard C, Carlsson B, Dahlgren S, Larsson B, Narbro K, Sjöström CD, et al. Lifestyle, diabetes, and cardiovascular risk factors 10 years after bariatric surgery. N Engl J Med. 2004;351(26):2683-93.

3. Angrisani L, Santonicola A, lovino P, Vitiello A, Higa K, Himpens J, Buchwald H, Scopinaro N. IFSO worldwide survey 2016: primary, endoluminal, and revisional procedures. Obes Surg. 2018;28(12):3783-94.

4. Yang P, Chen B, Xiang S, Lin XF, Luo F, Li W. Long-term outcomes of laparoscopic sleeve gastrectomy versus Roux-en-Y gastric bypass for morbid obesity: results from a meta-analysis of randomized controlled trials. Surg Obes Relat Dis. 2019:15(4):546-55.

5. Doumouras AG, Saleh F, Anvari S, Gmora S, Anvari M, Hong D. Mastery in bariatric surgery: the long-term surgeon learning curve of Roux-en-Y gastric bypass. Ann Surg. 2018;267(3):489-94.

6. Nguyen NT, Paya M, Stevens CM, Mavandadi S, Zainabadi K, Wilson SE. The relationship between hospital volume and outcome in bariatric surgery at academic medical centers. Ann Surg. 2004;240(4):586-593 discussion 593-584.

7. Mutter D, Vix M, Dallemagne B, Perretta S, Leroy J, Marescaux J. WeBSurg: an innovative educational Web site in minimally invasive surgery-principles and results. Surg Innov. 2011;18(1):8-14.
8. Ferhatoglu MF, Kartal A, Ekici U, Gurkan A. Evaluation of the reliability, utility, and quality of the information in sleeve gastrectomy videos shared on open access video sharing platform YouTube. Obes Surg. 2019;29(5):1477-84.

9. Agrawal S. Impact of bariatric fellowship training on perioperative outcomes for laparoscopic Roux-en-Y gastric bypass in the first year as consultant surgeon. Obes Surg. 2011;21(12):1817-21.

10. Lo HC. The learning curve of one anastomosis gastric bypass and its impact as a preceding procedure to Roux-en Y gastric bypass: initial experience of one hundred and five consecutive cases. BMC Surg. 2020;20(1):37.

11. Kasama K, Mui W, Lee WJ, Lakdawala M, Naitoh T, Seki Y, Sasaki A, Wakabayashi G, Sasaki I, Kawamura I, et al. IFSO-APC consensus statements 2011. Obes Surg. 2012;22(5):677-84.

12. Magro DO, Geloneze B, Delfini R, Pareja BC, Callejas F, Pareja JC. Long-term weight regain after gastric bypass: a 5-year prospective study. Obes Surg. 2008;18(6):648-51.

13. Schwartz ML, Drew RL, Chazin-Caldie M. Factors determining conversion from laparoscopic to open Roux-en-Y gastric bypass. Obes Surg. 2004;14(9):1193-7.

14. Thorell A, MacCormick AD, Awad S, Reynolds N, Roulin D, Demartines N, Vignaud M, Alvarez A, Singh PM, Lobo DN. Guidelines for perioperative care in bariatric surgery: enhanced recovery after surgery (ERAS) society recommendations. World J Surg. 2016;40(9):2065-83.

15. Schauer PR, Ikramuddin S. Laparoscopic surgery for morbid obesity. Surg Clin North Am. 2001;81(5):1145-79.

16. Lord JL, Cottam DR, Dallal RM, Mattar SG, Watson AR, Glasscock JM, Ramanathan R, Eid GM, Schauer PR. The impact of laparoscopic bariatric workshops on the practice patterns of surgeons. Surg Endosc. 2006;20(6):929-33.

17. Oliak D, Owens M, Schmidt HJ. Impact of fellowship training on the learning curve for laparoscopic gastric bypass. Obes Surg. 2004;14(2):197-200.

18. Sommer T, Larsen JF, Raundahl U. Eliminating learning curve-related morbidity in fast track laparoscopic Roux-en-Y gastric bypass. J Laparoendosc Adv Surg Tech A. 2011;21(4):307-12.

19. Rapp AK, Healy MG, Charlton ME, Keith JN, Rosenbaum ME, Kapadia MR. YouTube is the most frequently used educational video source for surgical preparation. J Surg Educ. 2016;73(6):1072-6.

20. Zendejas B, Cook DA, Hernández-Irizarry R, Huebner M, Farley DR. Mastery learning simulation-based curriculum for laparoscopic TEP inguinal hernia repair. J Surg Educ. 2012;69(2):208-14.

21. Oliak D, Ballantyne GH, Weber P, Wasielewski A, Davies RJ, Schmidt HJ. Laparoscopic Roux-en-Y gastric bypass: defining the learning curve. Surg Endosc. 2003;17(3):405-8.

22. Andrew CG, Hanna W, Look D, McLean AP, Christou NV. Early results after laparoscopic Roux-en-Y gastric bypass: effect of the learning curve. Can J Surg. 2006:49(6):417-21.

23. Shin RB. Evaluation of the learning curve for laparoscopic Roux-en-Y gastric bypass surgery. Surg Obes Relat Dis. 2005;1(2):91-4.

24. Nguyen NT, Rivers R, Wolfe BM. Factors associated with operative outcomes in laparoscopic gastric bypass. J Am Coll Surg. 2003;197(4):548555 discussion 555-547.

25. ASMBS Fellowship Certificate. https://asmbs.org/professional-education/ fellowship.

26. Ballesta-Lopez C, Poves I, Cabrera M, Almeida JA, Macias G. Learning curve for laparoscopic Roux-en-Y gastric bypass with totally hand-sewn anastomosis: analysis of first 600 consecutive patients. Surg Endosc. 2005; 19(4):519-24

27. Shen SC, Tsai CY, Liao CH, Liu YY, Yeh TS, Liu KH. Learning curve of laparoscopic Roux-en-Y gastric bypass in an Asian low-volume bariatric unit. Asian J Surg. 2018;41(2):170-5.

28. Huang CK, Lee YC, Hung CM, Chen YS, Tai CM. Laparoscopic Roux-en-Y gastric bypass for morbidly obese Chinese patients: learning curve, advocacy and complications. Obes Surg. 2008;18(7):776-81.

29. Shikora SA, Kim JJ, Tarnoff ME, Raskin E, Shore R. Laparoscopic Roux-en-Y gastric bypass: results and learning curve of a high-volume academic program. Arch Surg. 2005;140(4):362-7.

30. Wehrtmann FS, de la Garza JR, Kowalewski KF, Schmidt MW, Müller K, Tapking C, Probst P, Diener MK, Fischer L, Müller-Stich BP, et al. Learning curves of laparoscopic Roux-en-Y gastric bypass and sleeve gastrectomy 
in bariatric surgery: a systematic review and introduction of a standardization. Obes Surg. 2020;30(2):640-56.

31. Parmar CD, Bryant C, Luque-de-Leon E, Peraglie C, Prasad A, Rheinwalt K, Musella M. One anastomosis gastric bypass in morbidly obese patients with $\mathrm{BMI} \geq 50 \mathrm{~kg} / \mathrm{m}(2)$ : a systematic review comparing it with Roux-En-y gastric bypass and sleeve gastrectomy. Obes Surg. 2019;29(9):3039-46.

32. Lee WJ, Almalki OM, Ser KH, Chen JC, Lee YC. Randomized controlled trial of one anastomosis gastric bypass versus Roux-En-Y gastric bypass for obesity: comparison of the YOMEGA and Taiwan studies. Obes Surg 2019;29(9):3047-53

\section{Publisher's Note}

Springer Nature remains neutral with regard to jurisdictional claims in published maps and institutional affiliations.
Ready to submit your research? Choose BMC and benefit from:

- fast, convenient online submission

- thorough peer review by experienced researchers in your field

- rapid publication on acceptance

- support for research data, including large and complex data types

- gold Open Access which fosters wider collaboration and increased citations

- maximum visibility for your research: over $100 \mathrm{M}$ website views per year

At BMC, research is always in progress.

Learn more biomedcentral.com/submissions 